\title{
Correction to: Sub-range Jacobi polynomials
}

\section{Walter Gautschi ${ }^{1}$}

Published online: 7 May 2019

(C) Springer Science+Business Media, LLC, part of Springer Nature 2019

\section{Correction to: Numer. Algorithms 61:649-657 (2012)}

https://doi.org/10.1007/s11075-012-9556-z

The first equation in Eq. (2.9) should read

$$
\alpha_{k}=\frac{1}{2}\left[(1+c) a_{k}-1+c\right], \quad k \geq 0 .
$$

The error was detected while programming the procedure described in Section 3 of the paper and comparing the results for $c=0$ with earlier results obtained more directly (and correctly) by the cited Matlab function $r_{-}$subjacobi $0 . \mathrm{m}$.

Publisher's note Springer Nature remains neutral with regard to jurisdictional claims in published maps and institutional affiliations.

The online version of the original article can be found at https://doi.org/10.1007/s11075-012-9556-z.

Walter Gautschi

wgautschi@purdue.edu

1 Department of Computer Sciences, Purdue University, West Lafayette, IN 47907-2066, USA 